\title{
THE INTEGRATION OF LEAN MANUFACTURING AND LEAN
}

\section{MAINTENANCE TO IMPROVE PRODUCTION EFFICIENCY}

\section{IMANE AL MOUZANI \& DRISS BOUAMI}

LQSM, Mohammadia Engineering School (EMI), Rabat, Morocco

The lack of an implementation roadmap always deters companies from choosing lean manufacturing as its major management approach to achieve excellence; this paper proposes another improvement strategy to deliver manufacturing excellence, which is Lean maintenance. Many researchers have written about lean manufacturing, but lean maintenance is a new concept, which is few treated in research, lean maintenance is not a subset of lean manufacturing but it is a cardinal prerequisite for success as a lean manufacturer. Therefore, the aim of the current paper is to compare Lean Maintenance approach to Lean Manufacturing and Total Productive Maintenance (TPM) and finally investigate the specific characteristics of the Lean Maintenance approach in order to ensure effective success of the implementation of this approach.
\end{abstract}

KEYWORDS: Lean Manufacturing, Lean Maintenance, Total Productive Maintenance \& Manufacturing Excellence

Received: Nov 25, 2018; Accepted: Dec 15, 2018; Published: Jan 30, 2019; Paper Id.: IJMPERDFEB201957

\section{INTRODUCTION}

The globalization of competition, the complexity of the economy and the plethora of information available today place companies in a more than shifting context with which they must cope. This makes it harder for companies to predict political, social, economic, technological and industrial developments. However, they must be able to define a distant vision of the future while managing changes that are more frequent. Reducing delays between innovations, planning horizons and reducing development costs is necessary. Accelerating change becomes a constant feature of business life. Companies need methodological help to explore several areas, to process a lot of information, to define their future strategy, to develop new and more complex products and to industrialize rapidly.

The panorama of certification is broad, and it is a good approach to take the first step towards excellence. Despite its proven contributions, certification is not the total answer to the aspirations of companies, nor a sufficient passport to excellence. Faced with this situation, companies must reorganize their strategy, in order to be ready to meet customer requirements; the goal is to quickly provide products that combine quality and competitive price.

In this sense, Lean concept has conquered different economic sectors and most of the company's processes, positioning itself as an inevitable concept to improve the performance of the company. Lean is a lever that enables the company to continually improve its processes, reduce overheads and meet the growing and diverse needs of its customers, but it can never be achieved without maximum reliability and availability Equipment because of their direct impact on the quality, cost and delivery of products or services. Then companies must 
define the most appropriate maintenance strategy to achieve the required performance of the production system.

Moreover, while Lean Manufacturing is a well-known concept among industrialists and researchers, Lean maintenance is less well known and little processed by researchers.

Thus, in this paper, we study an approach based on the Lean Manufacturing and Lean Maintenance tools. We also propose improvement actions to optimize the production and maintenance activities that contribute to the improvement of the performance of production equipment and led to manufacturing excellence.

First, a conceptual analysis of Lean maintenance will be dealt with thoroughly. Second, we position the Lean maintenance approach as one of the other optimization and performance improvement approaches such as Lean Manufacturing and Total Productive Maintenance (TPM).

\section{LEAN MANUFACTURING}

In the 1960s, Toyota was the instigator of the Lean philosophy by combining the concepts of takt time, continuous flow and the flexibility dimension (reduction of series change times, versatile operators, etc.). In the 1970s, Toyota industrialized and "systemized" its Lean concept via the Toyota Productive System (TPS), a philosophical and practical approach aimed at increasing productivity while eliminating wastage at all levels of the industry, from the supplier to the end customer.

\subsection{Definition of the Lean Approach}

There is a plethora of different definitions of the lean concept, but the core idea still the same. Lean manufacturing is an operational strategy that continuously shortens the cycle time between customer order and shipment by eliminating waste.

\subsection{Principles of the Lean Concept}

The book "Lean Thinking" laid out five principles of lean manufacturing. Therefore, it defines them as a five-step process for the implementation of lean concepts (Womack, 1996):

- Define value from the customer perspective.

- Map the value stream and eliminate all non-value-adding steps.

- Create flow. Eliminate functional barriers and identify ways to improve lead-time to ensure the processes are smooth from the customer order is received through to delivery.

- Establish a pull system; Lean manufacturing concept uses a pull system instead of push system.

- Pursue perfection with continual process improvement.

\subsection{Pillars of the Lean Concept}

The three main problems of any production system (Drew et al, 2004):

- Muda: waste.

- Muri: Instability. 
- Mura: variability

These problems lead to reduced quality, increasing delivery times and rising costs.

Model of Toyota house in figure 1 represents the main principles of lean and how they coexist (Liker, 2006).

When applied to a production system, it ensures the stability of the company's production system, standardize work methods, less errors and defects will occur, also production will flow smoothly without interruptions.

The two pillars of the Lean Manufacturing house (JIT and JIDOKA) are based on:

- Heijunka: is a Lean method for reducing the unevenness in a production process and minimizing the chance of overburden.

- Standardized Work: reduced variability of work processes.

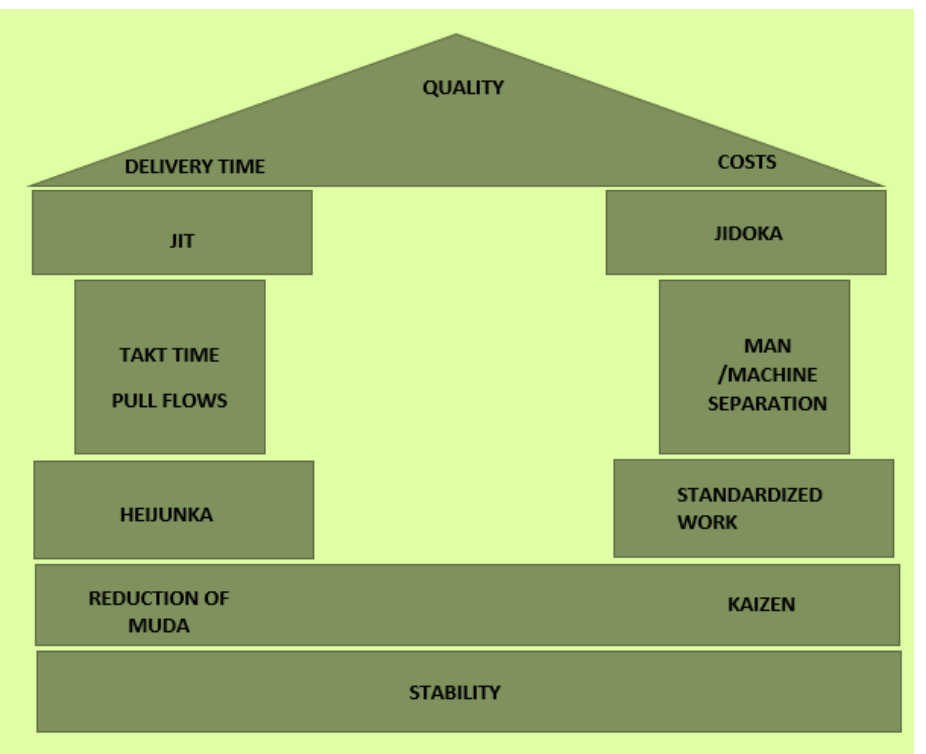

Figure 1: Model of the "Lean Production" System

\subsection{Lean Tools}

Lean Manufacturing relies on a multitude of tools to realize its objective, as shown in table 1 . These Tools include:

Table 1: Lean Manufacturing Tools

\begin{tabular}{|l|l|}
\hline \multicolumn{1}{|c|}{ Tools } & \multicolumn{1}{c|}{ Objective } \\
\hline 5S & Reduce wasted time \& motion at micro level. \\
\hline Heijunka & Reduces lead times and inventory \\
\hline HoshinKanri & $\begin{array}{l}\text { Ensures that progress towards strategic goals is } \\
\text { consistent and thorough - eliminating the waste } \\
\text { that comes from poor communication and } \\
\text { inconsistent direction. }\end{array}$ \\
\hline Jidoka & $\begin{array}{l}\text { Prevents problems on one station of a production } \\
\text { line from building inventory and creates urgency } \\
\text { to find permanent solutions. }\end{array}$ \\
\hline Just in Time & $\begin{array}{l}\text { Improves cash flow and reduces space } \\
\text { requirements. }\end{array}$ \\
\hline Kaizen & To improve work processes in a variety of ways. \\
\hline
\end{tabular}




\begin{tabular}{|c|c|}
\hline \multicolumn{2}{|r|}{ Table 1 : Contd., } \\
\hline $\begin{array}{l}\text { Maintenance productive total } \\
\text { TPM }\end{array}$ & $\begin{array}{l}\text { Ensure uptime, Improve process capability and } \\
\text { consistency }\end{array}$ \\
\hline Poka-yoke & Prevent the occurrence of mistakes or defects. \\
\hline Six sigma & $\begin{array}{l}\text { Improve quality, operational performance, } \\
\text { practices and systems }\end{array}$ \\
\hline $\begin{array}{l}\text { Single Minute Exchange of } \\
\text { Die (SMED) }\end{array}$ & $\begin{array}{l}\text { To minimize setup time and cost thereby freeing } \\
\text { capacity and enabling the production of very small } \\
\text { lots. }\end{array}$ \\
\hline Kanban & $\begin{array}{l}\text { To signal steps in the manufacturing process which } \\
\text { helps to reduce waste and maximize value. }\end{array}$ \\
\hline Total Quality Management & $\begin{array}{l}\text { Describes a management approach to long-term } \\
\text { success through customer satisfaction. }\end{array}$ \\
\hline Value stream mapping VSM & $\begin{array}{l}\text { Flowchart method to illustrate, analyse and } \\
\text { improve the steps required to deliver a product or } \\
\text { service }\end{array}$ \\
\hline
\end{tabular}

\subsection{Benefits of Lean System}

The benefits of implementing Lean cannot be limited into three categories: operational, administrative, and strategic improvements, (Kilpatrick, 2003). However, several studies have extended these benefits and have identified the positive impact of lean system in the creativity and reactivity of personnel (Enaghani et al, 2009). For example, the implementation of Lean generates improved staff motivation, improved inventory management, reduced lead times, and improved production efficiency, improved labour productivity, improved customer satisfaction, reduction of the time of series changes, Partner relations with customers and suppliers.

On the other hand, the Lean system also has negative impacts on employees and working conditions. Several research papers (Lyonnet, 2010; Tajri et al, 2011) have addressed this issue in terms of stress, a lot of training, hard work. Therefore, it is inevitable to take into account these negative consequences when designing and implementing a Lean system.

\section{LEAN MAINTENANCE}

Researchers have proposed several approaches and tools that contribute to the improvement of the performance of the production based on the Lean Manufacturing tools. Thus, in this article, we will propose a new approach to improve the performance of industrial equipment based, on the tools of Lean Maintenance and TPM. We will present also the main types of waste related to Lean Manufacturing and Lean Maintenance.

\subsection{Concept of Lean Maintenance}

The maintenance function is, by nature, a transversal activity of the company at the service of the other functions of which it reinforces the efficiency. However, it has been often neglected because it is often perceived as a source of expenditure.

However, the growth of global competition has generated remarkable changes that have affected the maintenance function by making its role more crucial to business success. Maintenance has become a main pillar for serving the production facilities to guarantee high productivity towards achieving the strategic objectives of organization in a competitive market. 
Indeed, the company must define the most appropriate maintenance strategy to achieve the required performance of its production system.

In this sense, Lean's objectives have been integrated into the maintenance objectives in order to formalize a new concept: Lean maintenance.

\subsubsection{Definition of Lean Maintenance}

The Lean Maintenance concept is a relatively new term, introduced in the last decade of the 20th century, but the principles are established in Total Productive Maintenance (TPM) (Smith et al, 2004). The Lean Maintenance theory is an advanced maintenance concept and the method aims to minimize the waste phenomenon.

Indeed, lean maintenance is a proactive maintenance operation employing planned and scheduled maintenance activities through total productive maintenance (TPM) practices (Smith, 2004). It relies on the combination of approaches, methods and tools of Lean manufacturing and maintenance. It is regarded as a benefit of maintenance to customers with minimal waste and a minimum of work, management effort, maintenance, spare parts, and energy (Levitt, 2008).

In summary, Lean Maintenance is a system that encompasses all maintenance principles and existing Lean techniques and aims to eliminate the various wastes identified in maintenance processes (Mostafaa et al, 2015).

\subsubsection{Principles of Lean Maintenance}

Lean maintenance represents adopting lean principles into the maintenance process, the figure 2 below demonstrate a proposed roadmap for implementing lean maintenance, this roadmap is based on five principles as stated by (Huang et al, 2012; Smith et al, 2004).

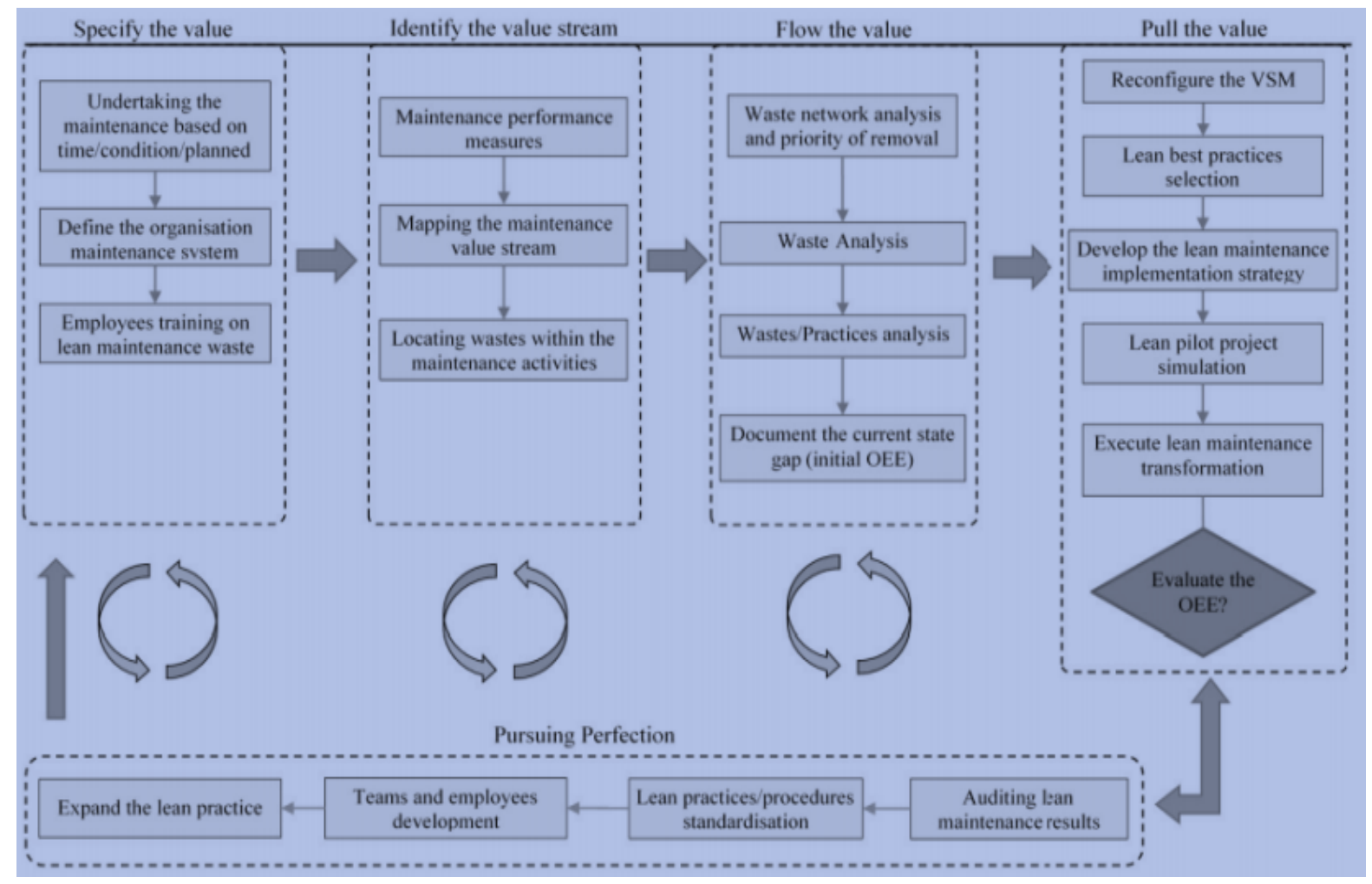

Figure 2: Proposed Lean Maintenance Roadmap 


\subsection{Lean Manufacturing VS Lean Maintenance}

Knowing that production and maintenance are two different processes, the Lean maintenance approach can never be an image of Lean manufacturing, although Lean manufacturing tools and principles have been introduced in the Lean maintenance.

The differences mentioned below show why Lean maintenance needs a different orientation than Lean Manufacturing.

- Production plans are based on sales forecasts. Therefore, they are driven by a precise schedule of work. However, corrective maintenance work follows a well-defined work schedule due to failures that occur randomly. Therefore, initiatives to ensure the effectiveness of the maintenance process such as just in time are limited.

- The concept of "production without wastage" is different between production and maintenance processes. For production, being productive without waste is rightly a daily management of the production process. For maintenance, this notion has an extra time perspective, producing without wastage means not replacing organs too early while avoiding failure.

- The final point to be developed is the collection and management of data. The improvement of production processes can be achieved by recording and acting on dynamic operational data. Data management and data collection is also useful for equipment maintenance, but it also requires static data such as the type and condition of equipment, the failure rate, etc.

Lean Maintenance must be designed with the specific characteristics of the maintenance processes in mind and be seen as a prerequisite for the success of Lean Manufacturing.

\subsection{Lean Maintenance Versus TPM}

Lean Maintenance is a powerful approach to help identify and eliminate waste related issues and deliver real bottom line improvements if implemented and managed in the right way. (Mostafaa et al, 2015).

In this context, in a rapidly evolving high-tech environment, the "traditional" TPM methodology has to be adapted to remain a viable means of improvement and provide the best results (Pomorski, 2004).

"Traditional" TPM is a set of participatory programs aimed at increasing the efficiency of equipment (productivity - quality - safety), minimizing life cycle costs and equipment losses and maximizing efficiency. However, the "traditional" TPM did not take into account all the wastes associated with the equipment. He only dealt with the set of equipment losses.

According to (Waeyenbergh et al, 2002) the six big categories of TPM losses are:

- Losses Related to Downtime: (1) equipment failure, (2) set-up and adjustment.

- Losses Related to Speed: (3) idling and minor stoppages, (4) reduced speed.

- Losses Related to Quality: (5) defects in the process, (6) reduced yield.

In contrast, modern TPM is mainly related to the value generated by the equipment. It now focuses on the entire production process to ensure that equipment is part of a series of value-added, and that it contributes "effectively" to the 
primary objective of value generation (Scodaniibbiio, 2009). Indeed, the TPM according to this vision must emphasize the added value of each equipment within the production process.

On the other hand, Lean maintenance puts the concept of value flow at the heart of equipment maintenance management. This corresponds perfectly to the needs of the decision-maker, particularly in terms of evaluation and control of maintenance costs. Indeed, the increase in downtime due to maintenance activities without added value can considerably increase maintenance costs (Kannanet al, 2007). Hence the advantage of eliminating any unnecessary moment between the stop of the machine and the completion of the repair work.

Without an overall view of the maintenance process provided by the value stream mapping, the means for improving performance may be consumed without priority and without optimization (deploying the TPM on machines with a much higher capacity if needed...). In addition, resources that require prompt and appropriate processing remain in a state of underperformance, which represents a loss of opportunity.

On the other hand, self-maintenance, which is an essential pillar for the deployment of the TPM, poses a risk of wanting to do too much and having false feedback: for example, repetitive micro-breakdowns not recovered by the TPM can cause complicated failures.

In this context, Lean maintenance is considered more than an evolution or update of the TPM philosophy (Kannanet al, 2007). It is an approach based on continuous improvement through the implementation of solutions for waste management, creating value for customers and stakeholders and improving the overall rate of return (Overall Equipment Effectiveness).

On the other hand, R. Smith postulates that the TPM is the basis of Lean maintenance (Smith et al, 2004), figure 3. In the same way, Oskar Olofsson thinks the resemblance between the TPM approach and Lean maintenance, in particular at the level of objectives (Olofsson, 2011).

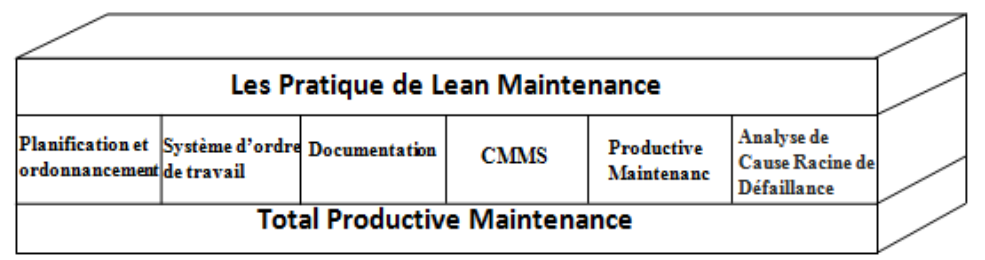

Figure 3: Lean Maintenance et la TPM (Smith et al, 2004)

\subsection{Lean Maintenance Tools}

The lean practices that suit the maintenance activities have been stated in previous studies:

- RCA (Root Cause Analysis): it identifies the different ways a piece; a process or equipment did fail. It is used to identify to "event type risks" and "people risks" along with the causes in the form of conditions and actions coupled with their interrelationships. The individual causes are examined in detail to define solutions to problems so that they don't recur

- RCM (Reliability-Centered Maintenance): RCM is a process used to determine the maintenance requirements of physical assets in their present operating context, it identifies the different ways a piece, equipment, or process could fail. RCM focuses on optimizing maintenance effectiveness. 
- CMMS: is a software that helps an organization track the status of maintenance tasks, such as equipment repair, it includes also planning and scheduling function, inventory control and management, and asset historical data.

- OEE (Overall Equipment Effectiveness): has become an industry standard, based on the availability, performance and output quality of the equipment, expressed in a percentage. OEE serves as a general and inclusive measurement of how will a company's manufacturing operation are performing.

- FMEA: failure mode and effects analysis: is a step-by-step approach for identifying all possible failures of a system. The purpose of FMEA is to make actions to eliminate or reduce failures, starting with the highest priority ones.

\subsection{Types of Waste}

Lean maintenance aims to create a smooth process and a high quality system to improve production and to have a finished product at the pace of the customer demand.

In this sense, we will focus in the following section on the main types of waste related to production and then related to maintenance.

\subsubsection{Production Wastes}

Ohno identified seven original types of waste within the Toyota Production System (TPS) (Ohno, 1998). Womack and Jones (Womack, 1996) added the eighth type of waste. The discussion of each waste type is as following:

- Overproduction: is making too much or too early, overproduction leads to high levels of inventory, which mask many of the problems within your organization.

- Defects: Every defective item requires rework or replacement, it wastes resources and materials, it creates paperwork, and it can lead to lost customers.

- Inappropriate Processing: using an inappropriate set of tools, procedures or systems, techniques, oversize equipment, perform processes that are not required by the customer.

- Excessive Transportation: movement of the materials or information, that cause waste in time and cost

- Waiting: this is an obvious waste, an enormous amount of time spending in waiting for information or goods, resulting long lead times

- Unnecessary Motion: moving more than necessary when doing work.

- Excess Inventory: excessive amount of storage that uses resources, but does not add any value for the customer.

- Underutilization of Employee: when an organization cannot obtain a maximum of benefit from its employees, cannot wisely wield its workforce, or cannot load them with work effectively.

\subsubsection{Maintenance Waste}

Like lean manufacturing, lean maintenance seeks to avoid waste. Each activities that not contribute to improving the availability of machine can be considered as a waste. The eight cardinal types of waste in the maintenance process can be discussed in the same manner as the production wastes. 
- Overproduction: is doing any work that does not add value. For example: performing preventive maintenance and predictive maintenance tasks more often than is necessary.

- Poor Inventory Management: Among the consequences of inaccurate inventory: High risk of a stock-out condition as parts will not be ordered on time, and parts will be flagged for re-ordering by the system even if not needed.

- Transportation: Unnecessary travel is the result of ineffective planning and scheduling.

- Waiting: waiting for equipment availability, job assignments, tools, parts, and instructions other crafts and permit approval, etc. Waiting is not a value-added activity and should be eliminated or reduced as much as possible.

- Process Waste: This is the result of a poor repair, and no enough time given to fix the properly repairs.

- Unnecessary Motion: this waste is usually found in preventive maintenance, doing inspection should be depending upon the criticality of that piece of equipment.

- Defects: it can be defined as leaving an asset in an unreliable condition. Inadequate training, inadequate/outdated procedures and not having the proper tools to do the proper job can lead to defect.

- Under-Utilization of Resources: maintenance technicians do non-value-adding works

\section{LEAN MAINTENANCE IMPLEMENTATION}

Manufacturing excellence is represented as going to zero in five dimensions, as illustrate in

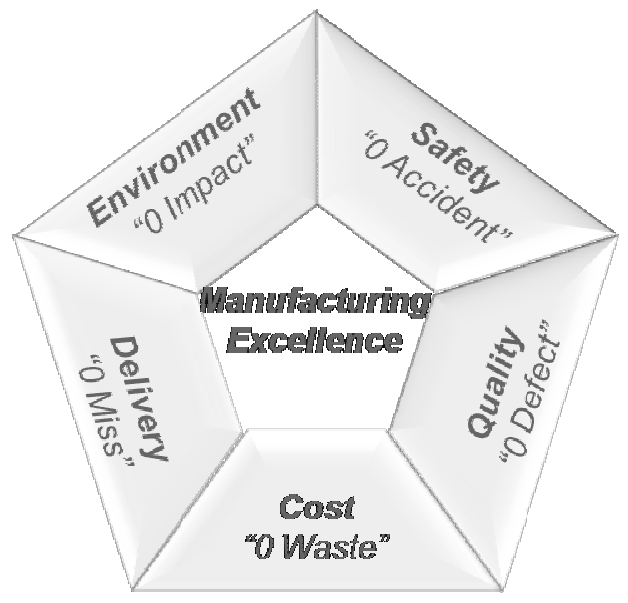

Figure 4: Manufacturing Excellence

Maintenance excellence is one of the essential deliveries to achieve overall Manufacturing excellence.

The goal of Lean maintenance is to deliver maintenance excellence with ZERO unplanned stops and optimized overall maintenance cost.

Ineffective maintenance will generate direct losses in delivery, waste, quality defects as well as safety and environmental issues.

Lean maintenance journey is visually represented by the following figure 5 : 


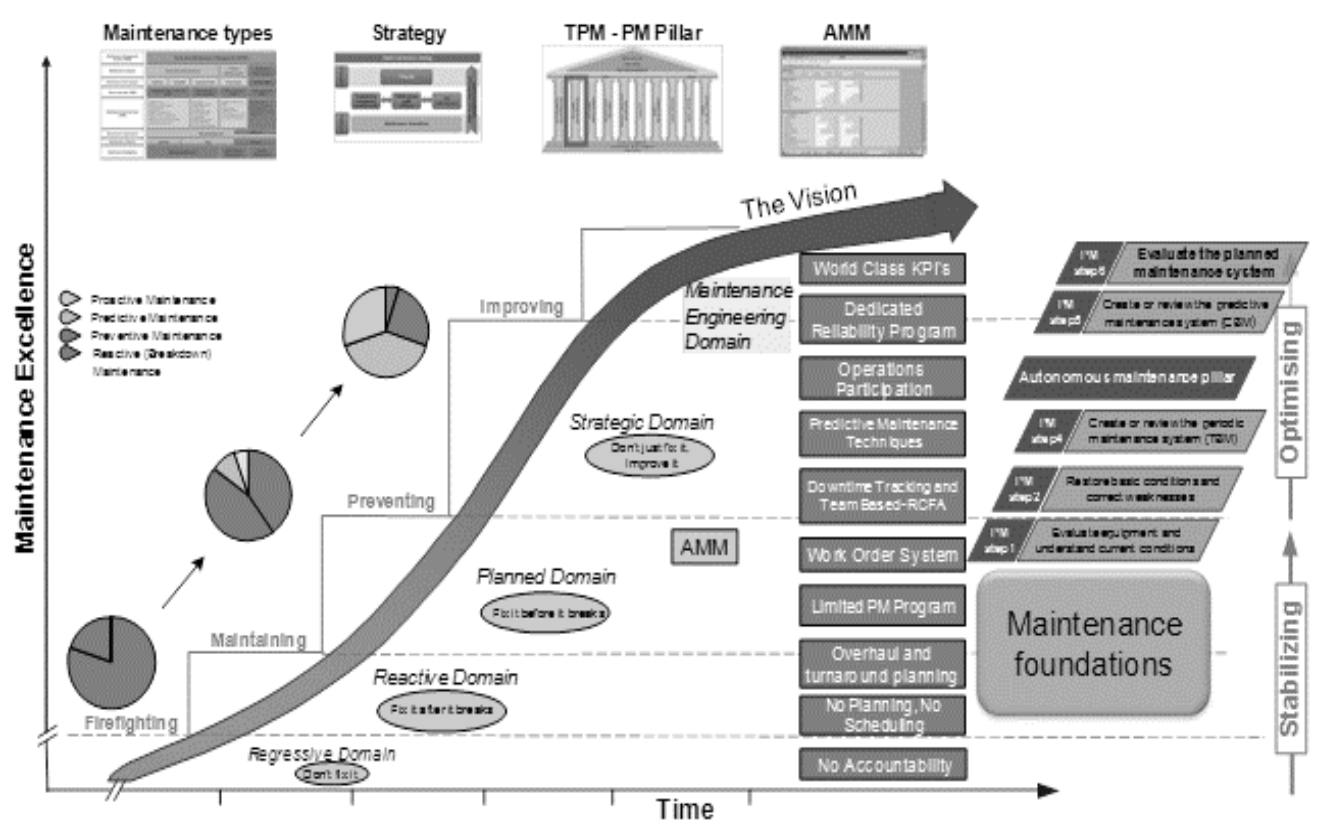

Figure 5: Lean Maintenance Journey

The right side of the graph shows how companies integrate maintenance strategy elements into the Lean maintenance journey. Maintenance foundations, PM and AM pillars provide a methodology to achieve maintenance excellence with AMM (Asset \& Maintenance management system) as a tool.

The Maintenance foundations and PM step1 are key activities that start the move of the factory from the reactive to the planned domain. PM steps and the Autonomous maintenance pillar are improvement activities. The combination will move the factory from the planned domain to the Strategic domain and further to world-class maintenance.

- Implementation gaps

The table 2 below summarizes the initial gaps and requirement of the lean maintenance program:

Table 2: Implementation Gaps

\begin{tabular}{|l|l|}
\hline \multicolumn{1}{|c|}{ Requirement } & \multicolumn{1}{c|}{ Action } \\
\hline $\begin{array}{l}\text { Engineering and production departments know the } \\
\text { components of Lean maintenance model. }\end{array}$ & \\
$\begin{array}{l}\text { It is clear that the maintenance strategy fully integrated } \\
\text { into Lean Maintenance journey and contribute to } \\
\text { overall Manufacturing excellence. }\end{array}$ & Train respective factory personnel on new strategy. \\
\hline $\begin{array}{l}\text { Lean maintenance strategy must be implemented across } \\
\text { all company facilities- }\end{array}$ & $\begin{array}{l}\text { Review/update OMP (operation master plan) to } \\
\text { include items for Maintenance strategy } \\
\text { implementation }\end{array}$ \\
\hline \multirow{2}{*}{$\begin{array}{l}\text { Correct maintenance order types and maintenance } \\
\text { activity types used consistently for any maintenance } \\
\text { activities across the factory }\end{array}$} & $\begin{array}{l}\text { Train factory maintenance staff on maintenance } \\
\text { classifications. }\end{array}$ \\
\cline { 2 - 2 } & $\begin{array}{l}\text { Ensure correct application of maintenance } \\
\text { classifications by work orders checking during } \\
\text { operational reviews }\end{array}$ \\
\hline \multirow{2}{*}{$\begin{array}{l}\text { Component/equipment based maintenance approach } \\
\text { implemented. Maintenance activities focused on } \\
\text { individual components and represented in 5W+1h } \\
\text { format. }\end{array}$} & $\begin{array}{l}\text { Train factory maintenance staff on } \\
\text { component/equipment based maintenance. }\end{array}$ \\
\cline { 2 - 2 } & $\begin{array}{l}\text { Build up plan to change to component /equipment } \\
\text { based maintenance gradually. }\end{array}$ \\
\cline { 2 - 2 } & $\begin{array}{l}\text { Establish maintenance plans review process to } \\
\text { comply with 5W+1H format }\end{array}$ \\
\hline
\end{tabular}




\begin{tabular}{|l|l|}
\hline \multicolumn{2}{|c|}{ Table 2: Contd., } \\
\hline \multirow{2}{*}{$\begin{array}{l}\text { Every factory must to establish and keep solid } \\
\text { maintenance foundations at all areas of the factory. }\end{array}$} & $\begin{array}{l}\text { Include maintenance foundations indicators as part } \\
\text { of operational reviews. }\end{array}$ \\
\cline { 2 - 2 } & $\begin{array}{l}\text { Assess typical gaps at the factory in all areas. } \\
\text { Create action plan to close existing gaps. Action } \\
\text { plan timing will depend on the factory maturity } \\
\text { level. }\end{array}$ \\
\hline
\end{tabular}

Further research could improve the proposed approach and provides a step-by-step lean maintenance model fully supporting the maintenance and improvement process and thus reach to excellence, this model will discuss all gaps and requirements generated by the current paper.

\section{DISCUSSION AND CONCLUSIONS}

In conclusion, the purpose of the study is to propose a new approach to improve equipment performance: Lean maintenance based on Lean manufacturing principles and tools

First, we focused on the Lean manufacturing concept that was formalized based on the Toyota Production System (TPS). It aims at optimizing and improving performance by acting on the origins of waste, while respecting a set of fundamental principles and using a set of predefined tools.

Second, we dealt with the Lean maintenance concept that integrates both Lean objectives and maintenance goals. Thus, Lean Maintenance aims to identify and eliminate sources of waste in all maintenance activities in order to provide a real improvement of the production system. We also the Lean tools whose deployment must be specific to the context of maintenance

Third, we positioned Lean Maintenance against the Total Productive Maintenance and Lean Manufacturing approaches. This study allowed us to highlight the specific characteristics of a Lean system maintenance and subsequently develop the necessary elements to develop a global reference framework to ensure a successful implementation of this system.

In perspective, we plan to address the issues of deployment of the Lean maintenance approach in the different industrial sectors to test its validity and reliability: how to successfully design and implement this approach at all areas of the factory? How to handle change?... etc.

\section{REFERENCES}

1. Drew J.; McCallum B.; S.Roggenhofer. (2004).Objectifs Lean:Eyrolles.

2. Enaghani M. R.; ArashpourM. R; Karimi M..(2009). the Relationship between Lean and TPM.

3. Huang J;Bian Y.; Cai W.(2012).Weapon Equipment Lean Maintenance. Chengdu, China, IEEE

4. Kannan S.; Li Y., Naveed A., El-Akkad Z.,(2007). Developing a maintenance value stream map. Department of Industrial and Information Engineering, Technical Societies and Divisions Lean Conference

5. Kilpatrick J. (2003). Lean principles : Manufacturing Extension Partnership

6. Levitt J., (2008), Lean maintenance, Industrial Press.

7. LikerJ..(2006). the Toyota Way:McGraw-Hill.

8. Lyonnet B. (2010).Identification des incontournables à la démarche Lean. 
9. Mostafaa S.; Dumrakb J.; SoltancH..(2015). Lean maintenance roadmap, 2nd International Materials, Industrial, and Manufacturing Engineering Conference, MIMEC2015,, Bali Indonesia

10. Ohno T..(1998). Toyota Production System: Beyond Large-Scale Production; Productivity Press.

11. Olofsson O..(2011). TPM / Lean Maintenance.

12. Pomorski T. R.. (2004). Total Productive Maintenance (TPM) Concepts and Literature Review: Brooks Automation.

13. Scodaniibbiio C.. (2009).World-Class TPM - How to calculate Overall Equipment Effectiveness (OEE).

14. Smith R.; (2004); What Is Lean Maintenance, Elements that need to be in place for success, Maintenance Technology, 2004 $15-21$

15. Arbaeen, O., \& Mohammad, H. (2017). Creating Contemporary Corset Designs, for Ladies' Clothing.

16. Smith R.; Hawkins B.; (2004); Lean Maintenance: reduce costs, improve quality, and increase market share, Elsevier.

17. Tajri ; Cherkaoui A. ; 2011 ; Rôle de l'ergonomie cognitive dans la conception et l'implémentation réussie d'un Total Lean Environment, CPI, Oujda.

18. Waeyenbergh. G., Pintelon, L.. (2002); a framework for maintenance concept development; International Journal of Production Economics; 77, 299-313. Doi :10.1016/S0925-5273(01) 00156-6

19. Womack J.P, Jones D. T..(1996). Lean Thinking. 